\title{
LOS KERUS VIVOS EN CAPITAL AYLLU SORAGA Y SU PARTICIPACIÓN EN LA FIESTA DE LA VIRGEN DEL ROSARIO'
}

\author{
THE LIVING KERUS OF CAPITAL AYLLU SORAGA AND THEIR INVOLVEMENT \\ IN THE FEAST OF THE VIRGIN OF THE ROSARY
}

Gerardo MoraA \& Andrea Goytia ${ }^{B}$

En el ayllu Soraga (Oruro, Bolivia) cuentan que, hace poco más de un siglo, encontraron tres (pares de) kerus en una galería subterránea ubicada en plena capital del ayllu, entre medio de las casas. Recordaron que eran usados en tiempo de los Inkas y comprendieron que el socavón era de la "mamita" Virgen del Rosario. Decidieron entonces que los kerus se involucrarían en la fiesta de la virgen y las ceremonias relacionadas con el poder local. Abordaremos estos kerus como organismos vivos, describiremos su morfología, iconografía y participación en la Fiesta del Rosario. Nuestra propuesta de trabajo es que ellos son capaces de hacer espacio-tiempo, específicamente, aquel donde-cuando Soraga estaba vinculado al Inka, ajeno a la Colonia. Ese espacio-tiempo convive con el aquí-ahora, en la mentada celebración.

Palabras clave: qero, etnografía, Bolivia, fiesta, Soraga.

The people of ayllu Soraga (Oruro, Bolivia) tell the story of how, just over a century ago, three (pairs of) kerus cups were found in an underground chamber located in the middle of the ayllu, between the houses. They recalled that these cups were used in Inca times and that the adit belongs to Virgin of the Rosary. They then decided to incorporate the kerus cups into the celebration of the Virgin's feast day, and in local political ceremonies. We approach these kerus cups as living organisms, describing their shape, iconography and involvement in the Virgin of the Rosary celebrations. Our working hypothesis is that they are capable of creating space-time, specifically the where-and-when Soraga was linked to the Inca empire and not part of the colonial regime. That space-time coexists with the here-and-now in the abovementioned celebration.

Keywords: qero cup, ethnography, Bolivia, feast day, Soraga.

\section{VÍSPERA}

En este artículo, nos centraremos en la participación de tres pares de kerus $^{2}$ coloniales en la fiesta dedicada a la Virgen del Rosario en Capital Ayllu Soraga. Lo haremos a partir del material reunido en dos visitas realizadas a dicha localidad, en julio y octubre del año 2014. Primero reseñaremos el ayllu, luego describiremos los kerus y problematizaremos su participación en la Fiesta del Rosario, antes de discutir las implicancias de ella.

Soraga pertenece al municipio del Santuario de Quillacas, $2^{\mathrm{a}}$ sección de la provincia Eduardo Avaroa, departamento de Oruro, Bolivia (fig. 1). Dicho municipio cuenta con una población aproximada de 3.500 personas, de las cuales un tercio es trilingüe (aymara, quechua y español) y cerca de un $70 \%$ se dedica a la agricultura, la ganadería, la caza y/o la silvicultura (INE-PNUD 2005: 350).

Soraga también es llamado Soraya o Soraya de Quillacas, y a su poblado central se le conoce como Capital Ayllu Soraga. Hasta hace pocos años correspondía a una localidad dedicada al pastoreo, aunque hoy se sumó a la fiebre mundial por la quinua, en detrimento de la crianza de camélidos. Además, su población ha disminuido drásticamente en las últimas décadas. Muchas familias tienen por primera residencia el cercano poblado de Sevaruyo -o Sabaruyo-, nodo comunicacional (emplazado en plena carretera y vía ferroviaria, con buen acceso a telecomunicaciones, etc.) entre Oruro y Uyuni, así como polo agrícola y comercial, y punto de paso obligado cuando se

\footnotetext{
A Gerardo Mora, proyecto FONDECYT 1130431. Universidad San Sebastián, Facultad de Enfermería, email: gmorar@docente.uss.cl

B Andrea Goytia, proyecto FONDECYT 1134031, email: andreagoytiasanabria@gmail.com
} 


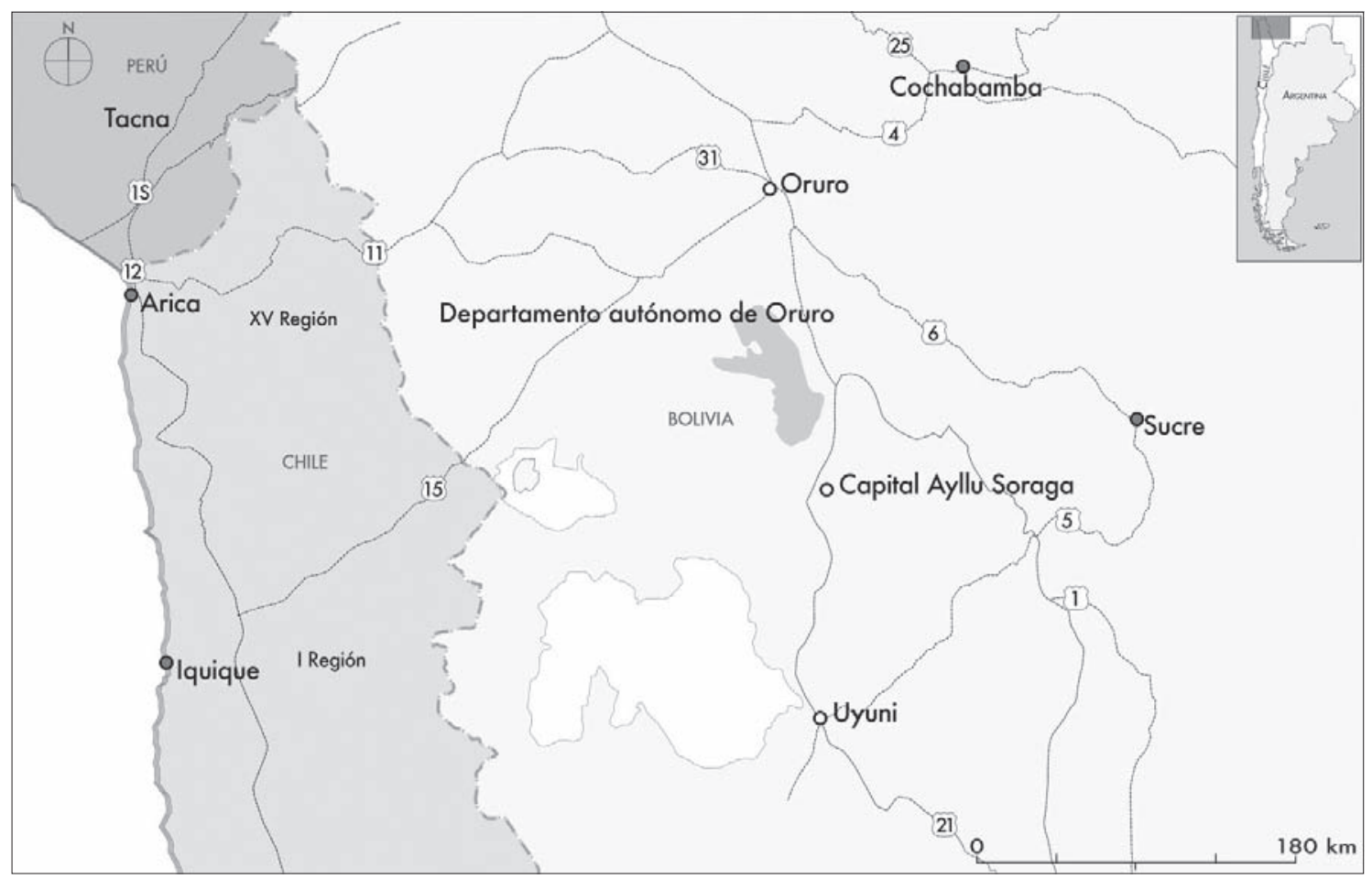

Figura 1. Mapa de localización de Capital Ayllu Soraga. Figure 1. Map showing the location of Capital Ayllu Soraga.

viaja entre las ciudades de Oruro, Sucre o Cochabamba y Capital Ayllu Soraga. También hay familias de Soraga que viven en la capital del departamento, tanto por las posibilidades laborales y educacionales, como por las comodidades que ellos encuentran en la urbe.

\section{KERUS}

Los kerus son recipientes elaborados para el consumo ritual de bebidas, hechos "habitualmente de madera, de forma troncocónica, más ancho por la boca que por la base, típico de varias culturas sur andinas" (Chaiña 2015: 8). Existen kerus de cerámica, vidrio, calabaza, metal, madera y otros materiales, y han sido fabricados en los Andes desde el Periodo Formativo Medio (3500 - 2700 AC) hasta la actualidad, sin embargo, académicamente, el término suele reservarse para aquellos elaborados hasta principios del siglo xIx. Flores Ochoa (1998), por otra parte, usa "keru" para referirse también a los vasos de arcilla Tiwanaku. En las tipologías que manejan los arqueólogos andinos suele usarse dicha expresión para referirse a todo vaso de cerámica de forma troncocónica o de campana invertida. Por otro lado, Ramos (2006: 106) sugiere usar "recipiente de madera con laca" para mayor precisión, además así se pueden incluir vasos que, con formas distintas (copas, pajchas, etc.), comparten connotaciones simbólicas.

Estos vasos siempre componen pares, "un vaso era para un individuo y el otro para invitar a otra persona o deidad a beber juntas", en cuanto a su apariencia, están "decorados con lujo y pintado a mano los diseños geométricos que siguen a las técnicas tradicionales de alfarería [...] sin embargo, pueden ser pintados con escenas narrativas que podrían ser acontecimientos históricos" (Chaiña 2015: 8).

El ayllu Soraga posee, actualmente, tres kerus, es decir, tres pares de vasos. En nuestro primer encuentro con ellos pudimos apreciar que, como periódicamente contienen líquidos (chicha de maíz y otras bebidas), en su interior la madera se está pudriendo. Cuando hicimos este comentario en voz alta, una señora nos respondió "sí, como nosotros". Esto nos llevó a abordar a los kerus como organismos vivos, partícipes de un proceso biológico y, por lo tanto, con características homologables a nuestra condición humana. 
Así, bajo una concepción antropogeneizadora (Ingold 2015: 120-124), consideraremos a los kerus como dotados de cuerpos, al modo de las talegas de Isluga estudiadas por Cereceda (2010), provistos de boca (apertura superior) y piel (superficie externa), cuya existencia está sometida a los mismos devenires que la del resto de los habitantes del ayllu. Por ello, no interpretaremos su presencia en actividades sociales como "uso" por parte de los seres humanos, sino como "participación" de los kerus en relación con los seres humanos y otros organismos.

Lo que suele entenderse como decoraciones son, para el caso de esta investigación, diversas entidades reconocibles como flores, animales, aves, montañas, arcoíris y personajes configurando series o escenas que habitan la piel de cada keru.

Algunas de dichas escenas corresponden a un espacio-tiempo distinto de la Colonia, en ellas está ausente la invasión europea y la extirpación de idolatrías, se trata del espacio-tiempo llamado ñawpa pacha (en voz quechua) o "tiempo del Inga" (como aparece en algunos documentos coloniales). A su vez, en otras escenas encontramos el espacio-tiempo colonial de las sociedades andinas, kay pacha, observable en las vestimentas y otros elementos distintivos (Martínez, Díaz \& Tocornal 2016: 10). La comprensión del espacio y el tiempo en las sociedades andinas es un tema altamente complejo, para los fines de este artículo baste considerar que ñawpa pacha y kay pacha no son, necesariamente, tiempos sucesivos ni espacios mutuamente excluyentes, podrían coexistir y encontrarse.

La gran mayoría de las comunidades en los Andes perdieron sus kerus en las campañas contra las idolatrías impulsadas durante la Colonia, y la represión que siguió a la fracasada rebelión de José Gabriel Thupa Amaro. A ello se sumó la paulatina desestructuración de las poblaciones del altiplano en la época republicana, por circunstancias económicas y políticas poco favorables que disminuyeron el número de sus habitantes y determinaron la pérdida de los territorios que solían ocupar. Hoy casi todos los vasos ceremoniales de data colonial yacen en museos y colecciones privadas, donde su existencia ha quedado suspendida.

En Soraga, un día cualquiera, a comienzos del siglo $\mathrm{xx}$, un hombre notó que una piedra en la entrada de su casa cambiaba levemente de posición de vez en cuando. ${ }^{3}$ La levantó y encontró el socavón de "la mamita Rosario". Uno más joven se animó a entrar superando el temor a los grandes sapos y encontró tres inkitas -según cuentan hoy-, cada cual con su keru "y sus cositas". Fue sacándolos de a poco. Un anciano presente afirmó que estos artefactos le recordaban al Inka y se decidió usarlos en la celebración de la fiesta de la Virgen del Rosario. Desde entonces así se hace, pues aunque los kerus nunca se encuentran directamente con ella, dicen que han "nacido por el socavón de nuestra Virgen del Rosario".

El resto del año dos pares de kerus permanecen bajo custodia del sacristán, un laico del lugar, mientras que el otro par queda con la pareja de pasantes para la próxima fiesta. ${ }^{6}$ Los kerus participan también en Domingo de Pascuas, y a comienzos del año en ceremonias vinculadas al cambio de ciertas autoridades en el ayllu.

Cabe hacer notar que, en Soraga, cuando hablan de keru se refieren a lo que nosotros podríamos llamar un par de kerus. Recordemos que se fabricaban y actuaban de a pares, es decir, se creaban dos artefactos idénticos en forma, tamaño y aspecto, que luego permanecían juntos para cumplir su cometido.?

Por otra parte, hay que destacar la asociación entre el Inka, estos kerus y el ayllu. Ante la presencia de estos kerus es común hablar del Inka, lo mismo cuando se cuenta la noble historia del ayllu Soraga. Si bien desarrollaremos este punto en otras publicaciones, es importante tenerlo en cuenta al momento de pensar la participación de los kerus en la Fiesta del Rosario.

\section{DESCRIPCIÓN}

En Soraga, los kerus tienen nombres propios. Los usaremos en este artículo, tal como lo hacen allá, para identificar a cada par. No obstante, agregaremos la distinción entre un keru A y otro B, para distinguir a los miembros de las duplas. No encontramos maneras (palabras, gestos, etc.) para diferenciar los componentes de los pares entre los habitantes del ayllu.

A partir de ciertas temáticas emergentes presentes en los kerus analizados, los presentamos en un orden cronológico hipotético, desde el más antiguo al más reciente (para los criterios de periodificación véase Martínez 2012; Martínez et al. 2014). Usaremos dibujos (figs. 2-4), medidas y textos para su descripción. Se dibujó el keru "A" de cada par, seleccionado como tal en virtud de la perceptibilidad favorable de las entidades presentes en las pieles de los kerus, según nuestras observaciones y criterios. Cada epidermis fue desplegada en una sola vista que mantuvo, en lo posible, la curvatura real de la 
superficie de cada cuerpo. Para elaborar estos desplegados, las entidades y otras marcas presentes en la piel de cada keru fueron calcados en una lámina plástica, transparente y dúctil. Los bocetos obtenidos fueron digitalizados, para su posterior tratamiento informático.

\section{Wara Wara}

En relación con un posible origen de su nombre contemporáneo, existe un motivo textil taquile, denominado "estrella" (Gisbert et al. 2010: 189), que corresponde a un rombo del cual emergen doce líneas, en cuatro grupos de a tres líneas paralelas entre sí, uno desde cada arista del polígono. Pensamos que la denominación Wara Wara (fig. 2, tabla 1) -"estrella" en aymara- guarda relación con el motivo textil antes mencionado. Esto no sería extraño, pues los kerus más tempranos "recuerdan mucho [...] las lógicas organizativas de los tejidos andinos" (Martínez et al. 2014: 93).

La piel de Wara Wara presenta líneas incisas que conforman motivos triangulares y romboidales, cuyos surcos se encuentran rellenos de resina. Para ser claros, no proponemos que la piel de este keru luzca el motivo denominado "estrella" (Gisbert et al. 2010: 189), sino que, en Soraga, cuando (re)encontraron este keru, hace más de un siglo, percibieron warawaranaka ("estrellas" en aymara) en su piel y por eso le llamaron Wara Wara. Con la expresión "percibir" nos referimos a interpretar, reconocer, leer, ver, etc., los cuales son procesos de difícil delimitación entre sí. Finalmente, cabe recalcar que el término Huarahuara (Bertonio 1984 [1612]: 149) alude a sustantivo singular, "estrella". El hecho de que en Soraga se haya optado por este término para nombrar los recipientes en cuestión -en lugar del apelativo Huarahuaranaca (Bertonio 1984 [1612]: 149), que significa "estrellas" - remarca el carácter "unitario" de los kerus dobles, desde la perspectiva de sus actuales dueños.

Por otra parte, a $0,5 \mathrm{~cm}$ del borde de la boca se aprecia una línea incisa que circunda el cuerpo de la pieza. A 5,3 cm del borde de la boca se encuentra una banda de $0,5 \mathrm{~cm}$ de ancho que sobresale ligeramente de la superficie externa, de su cuerpo con forma troncocónica.

Puntualmente, en Wara Wara A, a 7,7 cm del borde de la boca se observa un cinto de metal de 1,6 cm de ancho que circunda la pieza y está fijada a esta última mediante clavos, en un claro intento de restauración, reparación y recomposición. Los extremos opuestos de esta banda se han vinculado por fundición. La laca y

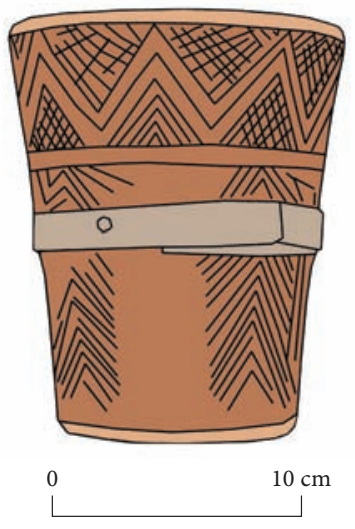

Figura 2. Wara Wara (dibujo de Andrea Goytia). Figure 2. Wara Wara (drawing by Andrea Goytia).

Tabla 1. Medidas básicas de cada miembro del par Wara Wara. Table 1. Basic measurements of each Wara Wara.

\begin{tabular}{l|c|c} 
Dimensiones $(\mathrm{cm})$ & Wara Wara A & Wara Wara B \\
Altura & 16,1 & 16,3 \\
\hline Diámetro superior & 13,8 & 14,0 \\
\hline Diámetro basal & 9,5 & 9,4 \\
\hline Grosor pared & 0,8 & 0,8
\end{tabular}

los motivos decorativos han desaparecido en amplias porciones de la superficie externa, probablemente debido a la manipulación de sus cuerpos. Lo mismo ha sucedido en toda la superficie interna, que además presenta resquebrajamientos.

Por su parte, en Wara Wara B, el borde de su boca ha perdido un trozo que ha sido remplazado por una porción de resina, la que se extiende por el cuerpo de la pieza, cubriendo, además, una fractura que parte de la boca y llega hasta la base. Flanqueando esta fractura -a 2, $5 \mathrm{~cm}$ del borde de su boca- se observan un par de orificios, posiblemente realizados para dar lugar y apoyo a unas grapas de unión ya ausentes. Por debajo, a 7,6 cm del borde de la boca, se han abierto dos orificios más. Estas cuatro aberturas también han sido rellenadas con resina. A $0,7 \mathrm{~cm}$ de su boca, y flanqueando otra fractura que se extiende $2,7 \mathrm{~cm}$ en sentido vertical a partir de la boca de la pieza, se evidencian otras dos aperturas para grapas de unión: una de ellas cerrada con resina y otra parcialmente abierta, únicamente se ha horadado un poco la superficie. 


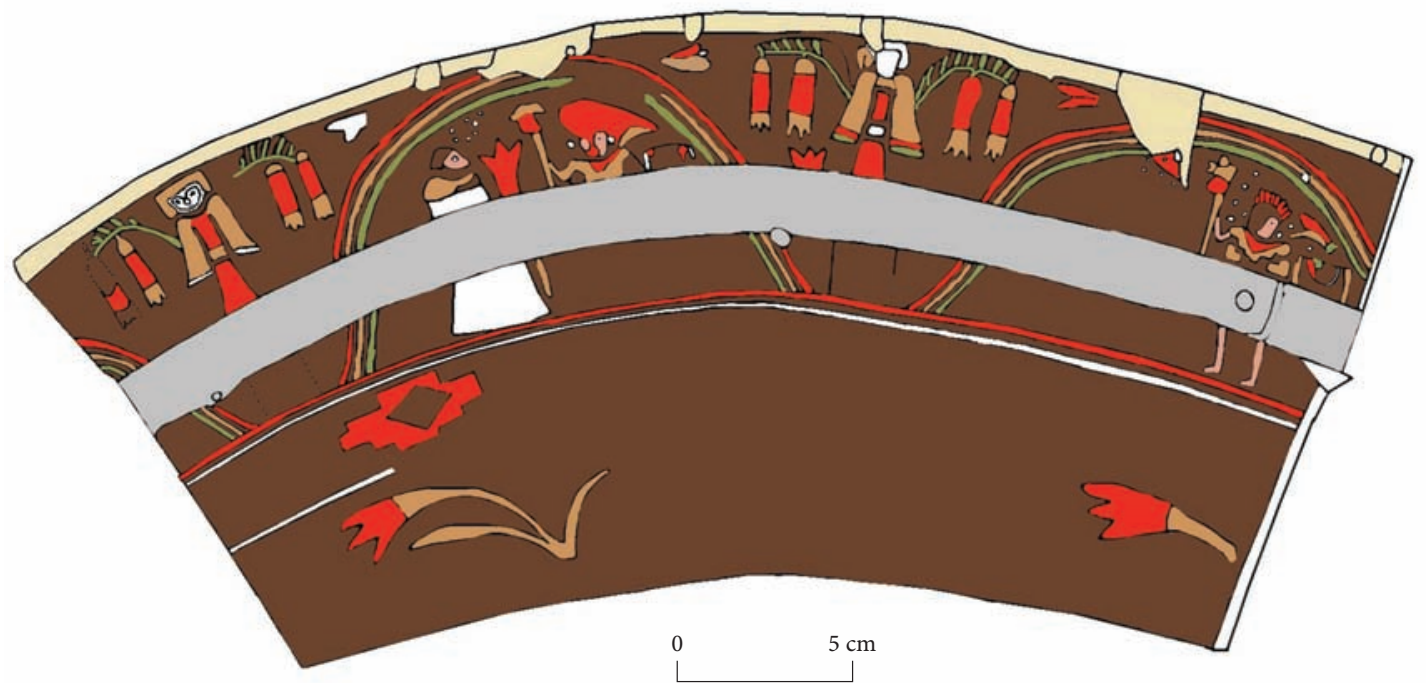

Figura 3. Chinchir Kuma (dibujo de Andrea Goytia). Figure 3. Chinchir Kuma (drawing by Andrea Goytia).

Tabla 2. Medidas básicas de cada miembro del par Chinchir Kuma. Table 2. Basic measurements of each Chinchir Kuma.

\begin{tabular}{l|c|c}
$\begin{array}{l}\text { Dimensiones } \\
(\mathrm{cm})\end{array}$ & $\begin{array}{c}\text { Chinchir } \\
\text { Kuma A }\end{array}$ & $\begin{array}{c}\text { Chinchir } \\
\text { Kuma B }\end{array}$ \\
\hline Altura & 19,2 & 19,0 \\
\hline Diámetro superior & 16,5 & 16,3 \\
\hline Diámetro basal & 11,6 & 11,7 \\
\hline Grosor pared & 0,8 & 0,9
\end{tabular}

\section{Chinchir Kuma ${ }^{8}$}

En Soraga nos señalaron que Chinchir Kuma (fig. 3, tabla 2) comparte nombre con la hierba Chachacoma (Senecio sp.). Poseen forma de campana invertida y su piel exterior está organizada en tres campos o bandas: una superior que presenta seres antropomorfos y fitomorfos, junto y por debajo de un motivo de arcoíris; al medio, tocapus, de los cuales solo es visible una figura escalonada, con un rombo de color rojo, ${ }^{9}$ y la banda inferior cuenta con cuatro kantutas (Cantua buxifolia).

A 5,4 cm del borde de la boca de Chinchir Kuma A se encuentra un cinto de metal, de $2,1 \mathrm{~cm}$ de ancho, se trata de una prótesis que rodea y cubre parte de la banda superior en un gesto restaurador, donde, en algunos casos, han desaparecido por completo los seres allí presentes, incluyendo la impronta de su pintura. Lo mismo sucedió en Chinchir Kuma B, solo que a 5,3 cm de su boca.

\section{Kalisa $^{10}$}

Proponemos que su nombre Kalisa (fig. 4, tabla 3) expresa cierta similitud morfológica con el cáliz, recipiente usado en la liturgia católica para consagrar el vino, dada su forma de campana invertida. Al respecto, cabe mencionar que algunos documentos hispanos y crónicas coloniales denominan "cáliz" a los kerus en poder de las poblaciones indígenas, recipientes usados tanto en ritos de tradición autóctona como en fiestas vinculadas al catolicismo popular (Flores Ochoa 1998: 46).

Su epidermis está organizada en tres bandas. La superior, con seres ornitomorfos, fitomorfos y geométricos: un par de aves que sostienen un estandarte intercalado con una flor en colores naranja y rojo. La del medio presenta dos tocapus intercalados: el primero consiste en un rectángulo que lleva en su interior un motivo en forma de " $\mathrm{M}$ " de color rojo; el segundo muestra una serie de figuras cuadrangulares, una dentro de otra, en naranja y rojo. Y en la inferior hay cuatro kantutas (Cantua buxifolia) con las puntas de las hojas pintadas de amarillo y el resto de color rojo.

Kalisa A perdió un fragmento de su boca, que fue remplazado, a modo de prótesis, por un pedazo de madera, sujeto a la pieza mediante una sutura metálica que traspasa dos orificios abiertos en su cuerpo. Una fractura vertical nace en la parte inferior del sucedáneo del fragmento desaparecido, recorriendo la superficie del cuerpo de la pieza hasta llegar a la base. A 10,2 cm del borde de la boca se ha colocado un cinto de metal 


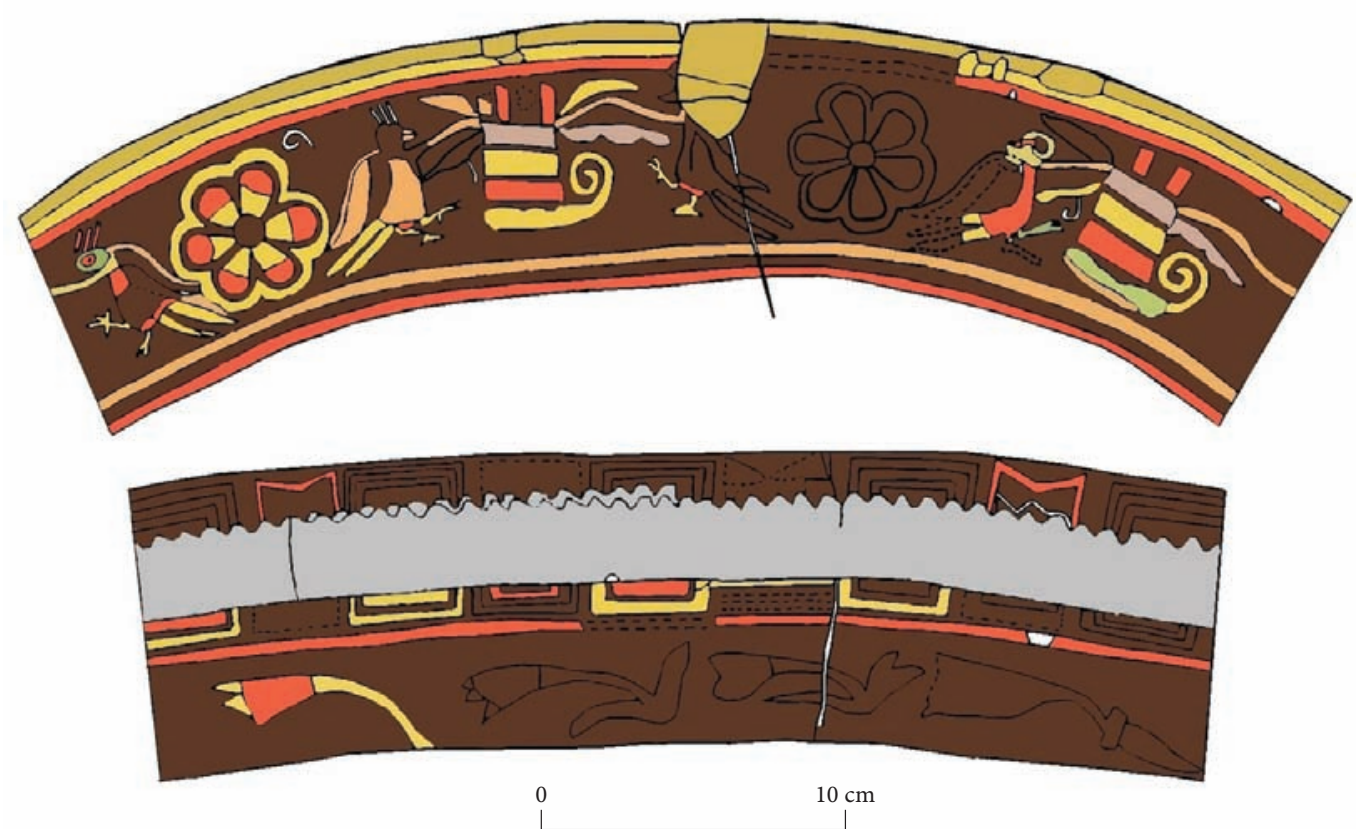

Figura 4. Kalis (dibujo de Andrea Goytia). Figure 4. Kalis (drawing by Andrea Goytia).

Tabla 3. Medidas básicas de cada miembro del par Kalis. Table 3. Basic measurements of each Kali.

\begin{tabular}{l|c|c} 
Dimensiones $(\mathrm{cm})$ & Kalisa A & Kalisa B \\
Altura & 17,2 & 16,7 \\
\hline Diámetro superior & 15,7 & 15,7 \\
\hline Diámetro basal & 10,2 & 10,2 \\
\hline Grosor pared & 0,7 & 0,8
\end{tabular}

de 2,7 cm de ancho, que circunda el cuerpo por sobre la banda del medio, a modo de faja. Tal vez sin intención, este agregado cubre los tocapus.

Gran parte de los seres presentes en su superficie han perdido el color, quedando solo la impronta donde estuvieron. Lo mismo sucedió con Kalisa B, donde ya es casi imposible identificar algunas criaturas.

A 9,9 $\mathrm{cm}$ del borde de la boca de Kalisa B se observa un cinto de metal de $2,6 \mathrm{~cm}$ de ancho que circunda el cuerpo, específicamente la banda del medio y tapando casi por completo los tocapus, de los cuales solo es posible ver los extremos superior e inferior). Una parte de este cinto, tal como en Kalisa A, es doble. Una fractura vertical parte del borde de la boca y continúa hasta llegar a la base. Por otra parte, se aprecian magulladuras en el borde de la boca y una fractura vertical que parte de esta última hasta llegar a la base. Finalmente, pequeños pedazos de coca han quedado pegados en la impronta de la pintura en su epidermis, la base exhibe rastros de mixtura y la superficie interna restos de chicha, todas evidencias de acciones recientes.

Llama nuestra atención que las intervenciones hechas a un keru fueron ejecutadas también sobre su par, en una innegable búsqueda de paridad quirúrgica y sensorial. Lo que hacen a uno lo hacen al otro. ¿Estaremos ante un indicio de la relevancia de (mantener) la semejanza perceptual entre ambos miembros de cada par? Hablamos de perceptual, pues estas intervenciones alteran la visualidad, la textura, el peso, etc., y otros aspectos sensibles de cada artefacto.

No hemos reunido antecedentes acerca del momento en que fueron hechas estas operaciones quirúrgicas, ni sobre quién las hizo. Dicen, en Soraga, que algunas de estas prótesis metálicas eran, originalmente, de oro macizo o plata, pero alguna persona mal intencionada las habría cambiado por las actuales. ${ }^{11}$

Si bien no es nuestro objetivo presente fechar estos kerus, desde las temáticas encontradas en sus superficies y los criterios de periodificación, a modo de hipótesis de trabajo, proponemos que Wara Wara sería inkaiko; Chinchir Kuma, pretoledano del siglo xvi y; Kalisa, de los siglos XVI o XVII, es decir, cercano a las reformas toledanas. ${ }^{12}$ Esto levanta mayores inquietudes sobre su hallazgo. ¿Cómo pudieron ser encontrados juntos, en un mismo socavón, hace poco más de un siglo? 
Tanto la datación de los kerus como la interpretación de sus nombres deben considerarse como resultados parciales de una investigación todavía en curso. Profundizaremos ambos aspectos en futuras publicaciones.

\section{EN LA FIESTA DEL ROSARIO}

En la víspera, por la mañana, un par de kerus es dispuesto en una mesa afuera de la casa del pasante, donde se harán las "costumbritas". Nos referimos a una mesa ritual, con un aguayo, sobre el que se colocan dos (pares de) choclos y dos (pares de) papas. Esta disposición en paridades, junto a los kerus, evidencia la relación de yanantin (Platt 1986), es decir, de la necesaria dualidad complementaria, como principio organizacional andino. Además, se coloca una chuspa con coca, junto a una sencilla escudilla, que también estaba en el socavón de la mamita Rosario. ${ }^{13}$

Desde dicha posición, el par de kerus puede observar el calvario del pueblo, el estandarte del pasante de este año, el Niño Jesús dentro de su caja que está envuelta en un manto blanco y la fajcha (faenamiento ritual de un llamo) que da inicio a la víspera.

Para la fajcha, unas parientes traen una recua de llamos a la casa del pasante. Allí escogen al animal que

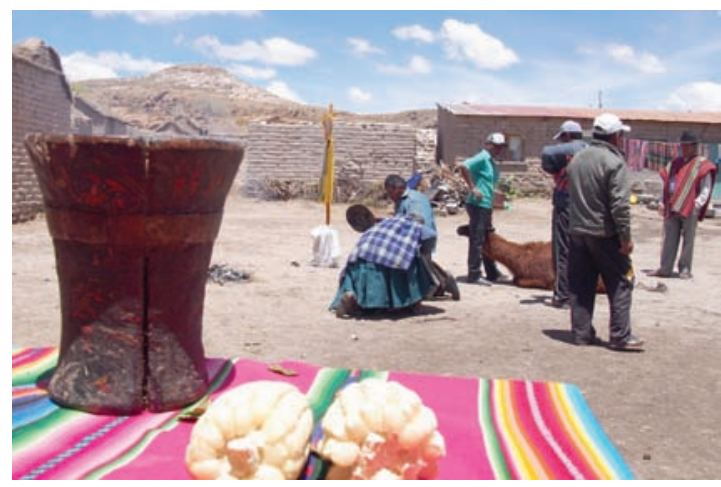

Figura 5. En la punta del cerro: el calvario. Frente a la mesa: el estandarte, el Niño envuelto y la familia del pasante participan de la fajcha (fotografía de Gerardo Mora). Figure 5. At the summit of the mount: the calvary. In front of the table: the standard, the swaddled Child Jesus, and the family of the feast host (pasante) participate in the Fajcha ritual (photo by Gerardo Mora).

será degollado y el resto es regresado a sus actividades habituales. A la criatura elegida se le atan las piernas y se le vendan los ojos. Es ubicado frente al estandarte y al Niño Jesús (fig. 5). Su cabeza apunta hacia unos cerros localizados al oriente de donde está el calvario, de los cuales poco pudimos averiguar y adonde nos desaconsejaron ir. De igual manera, la mirada de quien corta su cuello se dirige hacia esos cerros (fig. 6).

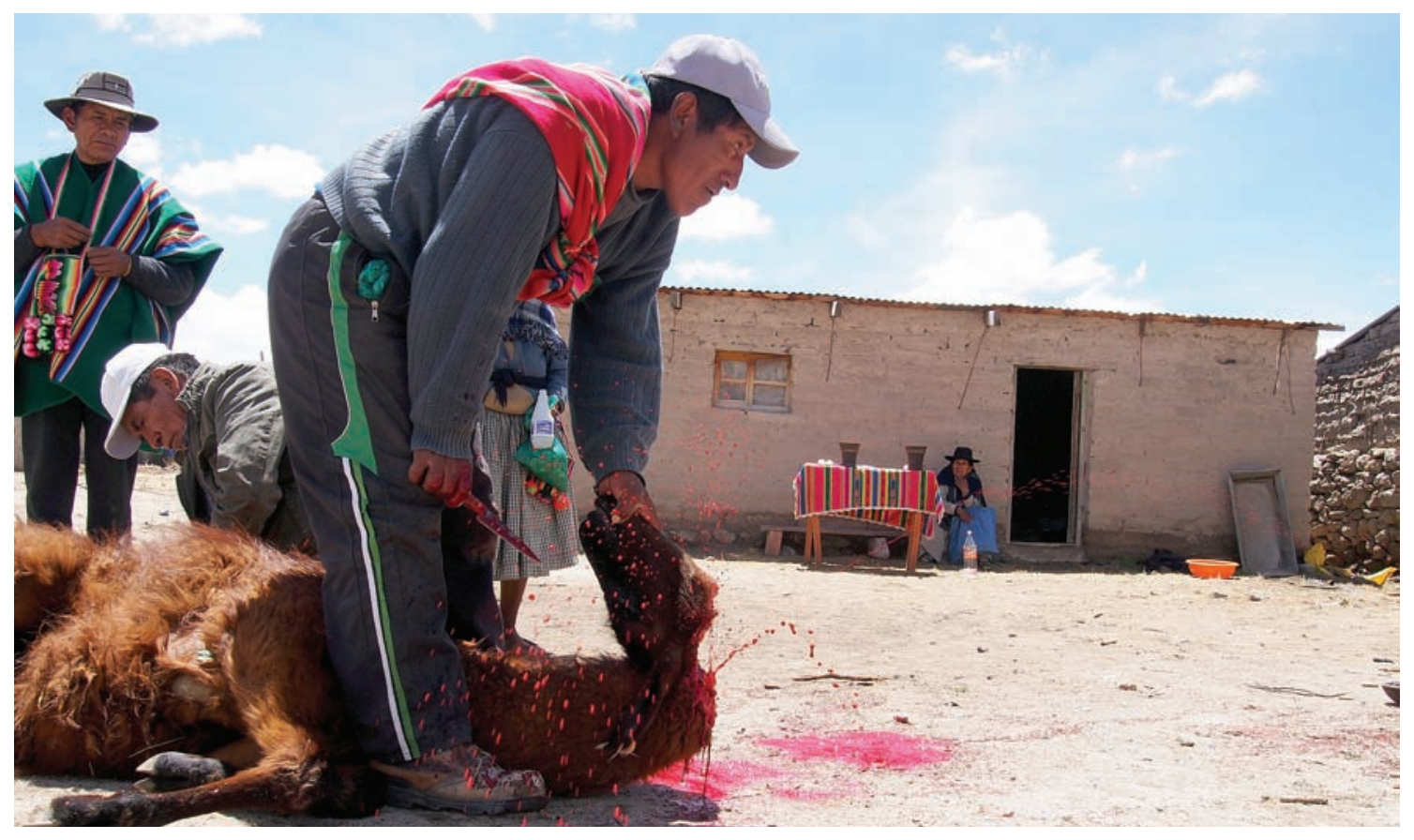

Figura 6. Desde la mesa el (par de) keru(s) brinda su presencia a la fajcha (fotografía de Gerardo Mora). Figure 6. On the table, the (pair of) keru(s) provides its presence to the Fajcha (photo by Gerardo Mora). 


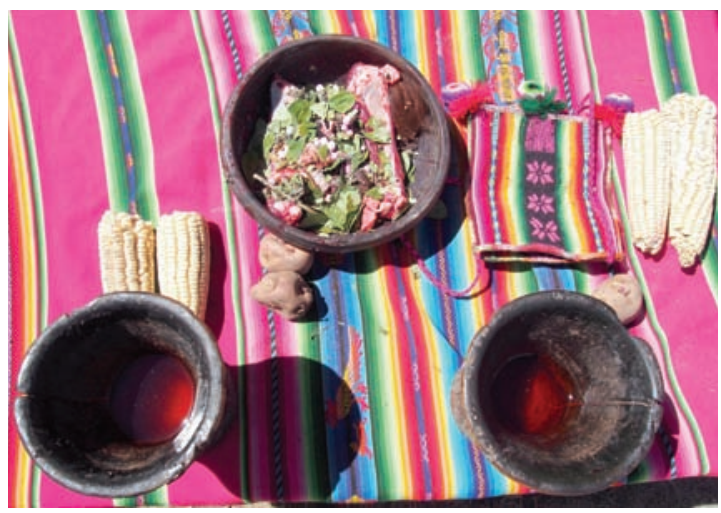

Figura 7. La mesa. Presentará diversas organizaciones durante la fiesta. En las costumbritas, cuando todavía no llegaba la chicha, se usó "refresquito" "para disimular" (fotografía de Gerardo Mora). Figure 7. "La mesa". The arrangement will change during the celebrations. In the "costumbritas", before the chicha arrives, "soda" was used "to disguise" (photo by Gerardo Mora).

Un poco de vellón, hueso y pezuñas del llamo son puestas en la escudilla y son challadas con hojas de coca, koba y pastillas dulces (fig. 7). ${ }^{14}$

El animal es completamente aprovechado. Su pecho cocido es colocado en la escudilla antes mencionada (fig. 8). Se dice que es la carne "más dulce". Todos comemos de ella. Tras la mesa, de manera rotativa, se van sentando autoridades locales y otras personas importantes.

Frente a la mesa, esto es, frente al par de kerus, se coloca un pullu (similar a una gran frazada) donde se va dejando la apxata que cada persona comprometió para esta fiesta. ${ }^{15}$ Se trata de ropa, coca, dinero, etc. Todo esto es cargado en aguayos por miembros de la familia del pasante.

Después de esto se realiza la misa de víspera, en la cual no participan los kerus. De hecho, para la fiesta acude un sacerdote católico a Capital Ayllu Soraga, quien jamás comparte espacio o tiempo con los kerus.

Por otra parte, un Niño Jesús que permanece en la iglesia de Capital Ayllu Soraga durante todo el año, participa de las procesiones y la fajcha de la fiesta de la Virgen del Rosario, su madre (fig. 9). Se trata de un soporte inicialmente creado dentro del sistema devocional católico, pero que hoy es parte de un metarrelato andino, pues actualiza la presencia del Inka en la Colonia y la actividad pastoril allí donde (no) es practicada (Mora \& Odone 2011).

Cuando este Niño Jesús se aproxima al par de kerus se evita el contacto entre ellos. Y si el Niño debe permanecer cerca del par de kerus es envuelto en una manta de estricto blanco, como sucede durante la fajcha (fig. 5).

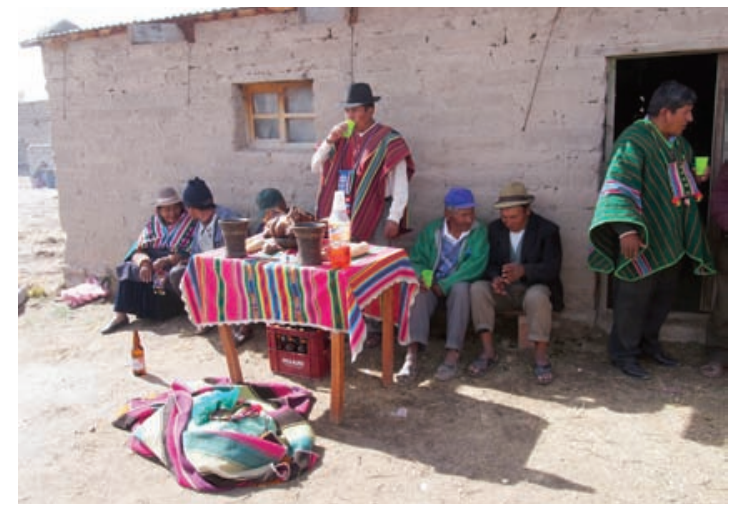

Figura 8. Por el resto de la víspera, la mesa será el centro de las acciones (fotografía de Gerardo Mora). Figure 8. For the rest of the "vispera", the table will be the center of activity (photo by Gerardo Mora).

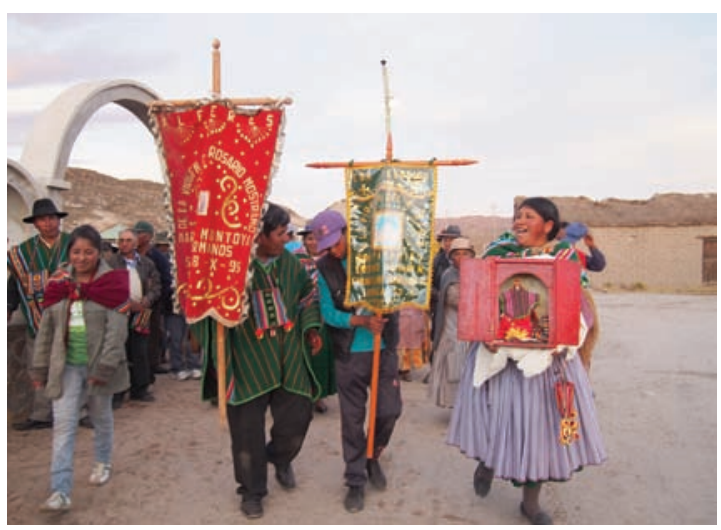

Figura 9. Niño Jesús en la cabecera de la procesión, cargado por una mujer (fotografía de Gerardo Mora). Figure 9. Infant Jesus at the head of the procession, carried by a woman (photo by Gerardo Mora).

¿Qué implica que los kerus no perciban ni sean percibidos por el sacerdote católico ni por el Niño Jesús? ¿Se evitan, se excluyen? Proponemos que los kerus pertenecen y crean un espacio-tiempo donde la Iglesia católica, su evangelización y extirpación, no existen. Es decir, son y hacen ñawpa pacha. El catolicismo y las entidades que le son propias, como el sacerdote, el Niño Jesús y la Virgen del Rosario, son y hacen kay pacha. Al menos durante la Fiesta del Rosario, en Soraga, no hay pacha donde organismos católicos coexistan con los kerus. Se acercan, actúan el mismo día, en calles aledañas. A veces el Niño pasa cerca de los kerus; a veces el cura prohíbe sutilmente el uso de hojas de coca. Durante la fiesta conviven ñawpa pacha y kay pacha, sin que sea posible trazar una frontera tajante entre ambos. Se complementan, en yanantin. 
Al día siguiente, durante la fiesta, el par de kerus está sobre la mesa, llenos de chicha de maíz, traída de Sucre, en espera de quienes vendrán a saludar. En un principio nos dijeron que los brindis se realizaban en riguroso orden, según la indicación de la autoridad originaria. Pero debemos aceptar que no pudimos reconocer ningún orden en la participación de los kerus. En un momento inesperado -para nosotros- alguien, un pariente del pasante que parecía buen conocedor de las costumbres, comenzó a bromear (en aymara) con la chicha y los kerus, señalando que nadie estaba tomando en ellos, que el pasante no era atento con sus invitados, que la autoridad no estaba llamando a beber. ${ }^{16}$ Entonces comenzaron a acercarse, en parejas, para tomar con el par de kerus (fig. 10). ¿ Habrán sido las bromas una manera de enmendar cierta omisión del pasante y la autoridad?, ¿ será el humor el gatillante (y compañero) habitual del beber en $\operatorname{keru}(s)$ ?, ¿tendrá el pasante que evidenciar su desconocimiento de los protocolos etílicos, para así poder aprenderlos públicamente y "pasar" la fiesta, en tanto rito de pasaje?

Frente a la mesa nos servimos la comida preparada a un costado de la casa del pasante, bailamos las morenadas y otros ritmos tocados por la banda de bronce, reímos, conversamos. En esto hay algo que pone en tensión nuestra propuesta. Los bronces son instrumentos de filiación europea. Se asocian, desde la gestualidad de su interpretación, con la vida urbana (Martínez C. 2001), y por su entrada a la musicalidad andina, con las milicias republicanas (Díaz 2009). Si asumimos que las ciudades actuales y las milicias nacionales son ajenas a ñawpa pacha ¿Será entonces que las melodías, y no el formato instrumental, hacen el espacio-tiempo? Habrá que escuchar con mayor atención esta música. ${ }^{17}$

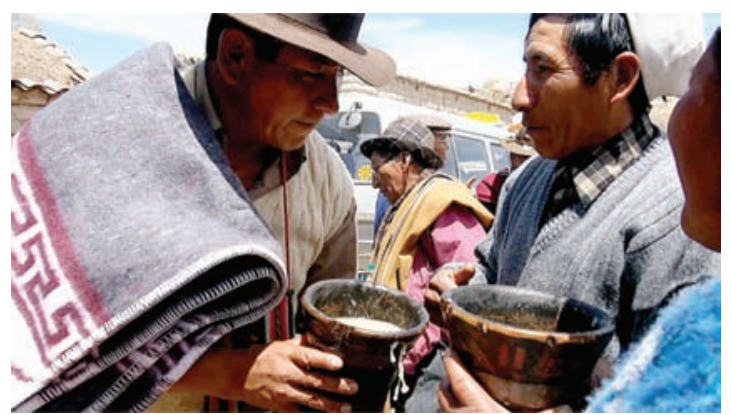

Figura 10. Antes de beber se conversa, se challa, se alza el keru (fotografía de Gerardo Mora). Figure 10. Before drinking, the people talk, sprinkle some of the beverage as an offering (challa), raise the keru (photo by Gerardo Mora).
$\mathrm{Al}$ atardecer se hizo la cuenta de quiénes habían cumplido con sus compromisos (apxata), de manera pública se mostraron los regalos, se contó el dinero y se registró por escrito todo lo traído. Luego, sin mayores aspavientos, el par de kerus fue guardado y la mesa desmontada, salvo por el aguayo. Por la noche, mientras los kerus "duermen" -según dicen en Soraga-, un conjunto electrónico anima a la concurrencia hasta altas horas.

Corresponde señalar que no es relevante cuál de los tres pares de kerus participan en cada instancia de la Fiesta del Rosario. Son intercambiados casi azarosamente y, al consultar por criterios de elección, nos señalaron que basta con la presencia de un par de kerus. Sabemos que el par más alto queda al cuidado del pasante del año próximo, pero desconocemos si esto tiene alguna implicancia.

Al día siguiente es el pago de la contribución territorial. La autoridad originaria oficia de alcalde cobrador, llega temprano al cabildo de arriba, en compañía de su esposa. Limpian el lugar y sacan un escritorio donde se formalizará la tributación.

Afuera del cabildo hay un bloque de piedra, de superficie horizontal, plana y lisa, sobre el cual se prepara una mesa: con un viejo aguayo, un puñado de coca aplastado con un trozo de ladrillo, un par de mojos, una botella pequeña rellenada con singani y un par de kerus (fig. 11). Todos los recipientes son delicadamente preparados. Los mojos se lavan en chicha traída en un gran cántaro de greda, y el interior del par de kerus es enjuagado con agua de un grifo, que proviene de una vertiente (fig. 12).

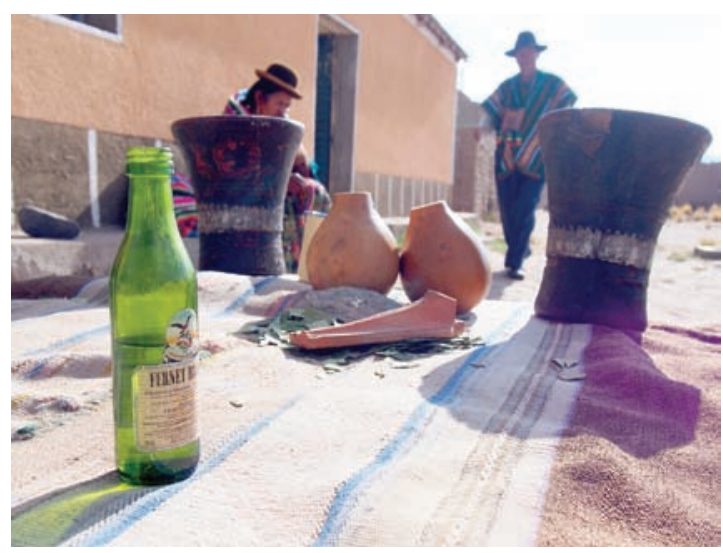

Figura 11. La mesa, la mama alcalde y el alcalde cobrador (fotografía de Gerardo Mora). Figure 11. The table, the mamaalcalde (Wife of the Mayor) and alcalde cobrador (Land tax collector) (photo by Gerardo Mora). 


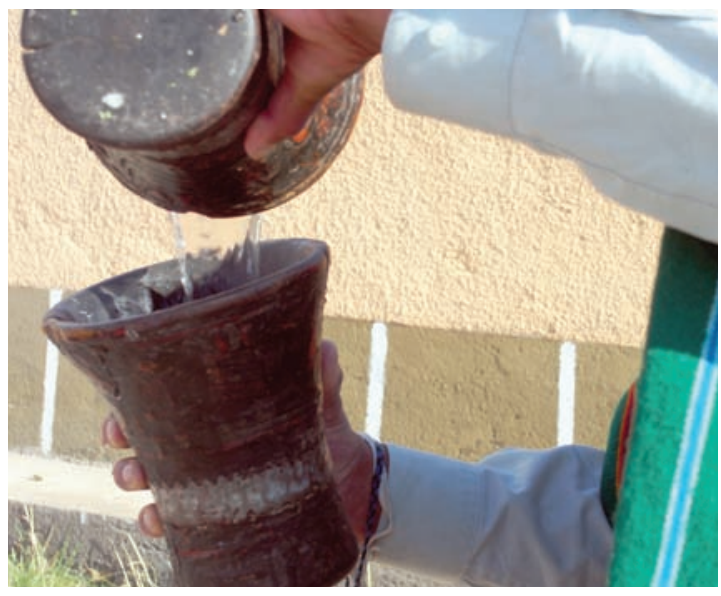

Figura 12. El (par de) de keru(s) apenas se enjuaga, no se restriega, ni siquiera se toca su interior (fotografía de Gerardo Mora). Figure 12. The (pair of) keru(s) is rinsed quickly, never washed, and the inside is hardly touched (photo by Gerardo Mora).

Hay quienes pagan de inmediato. Otros pasan a preguntar cuánto es y regresan más tarde con el dinero. Muchos reclaman que el cobro ha subido excesivamente. El alcalde cobrador no se cansa de explicar que ese dinero no es para uso personal, sino para adquirir cosas (maquinarias, herramientas, etc.) o hacer obras para la comunidad. Él muestra la nómina de los pagos ya recibidos como argumento (fig. 13). Cada pago no se realiza de mano a mano, el alcalde cobrador recibe el dinero en su manta y luego lo toma. Concretado cada pago el alcalde bebe chicha en (el par de) mojo(s) con quien ha cumplido. El par de kerus no se mueven. ${ }^{18}$

Con el paso de la mañana varios hombres se acomodan alrededor de la mesa (fig. 14). Las mujeres usan las bancas que están adosadas al cabildo. Todos beben cerveza Huari, "la rubia que no te engaña". El par de kerus permanece quieto.

Cuando ya casi todos los comuneros habían pagado su contribución territorial y la familia del alférez había pasado bailando con su banda de bronces, el profesor de la escuela de Capital Ayllu Soraga, quien lleva varios años trabajando allí, tomó un keru (fig. 15). Lo mismo hizo el juez de Capital Ayllu Soraga. Primero brindó el licenciado, después el juez (fig. 16).

Luego de eso, todos los presentes nos arrodillamos en dirección a los mismos cerros adonde apuntaban la cabeza del llamo de la fajcha y la mirada de quien lo degolló. Murmuraron largo rato mientras challaban coca, singani y alcohol. Después fuimos al otro cabil-

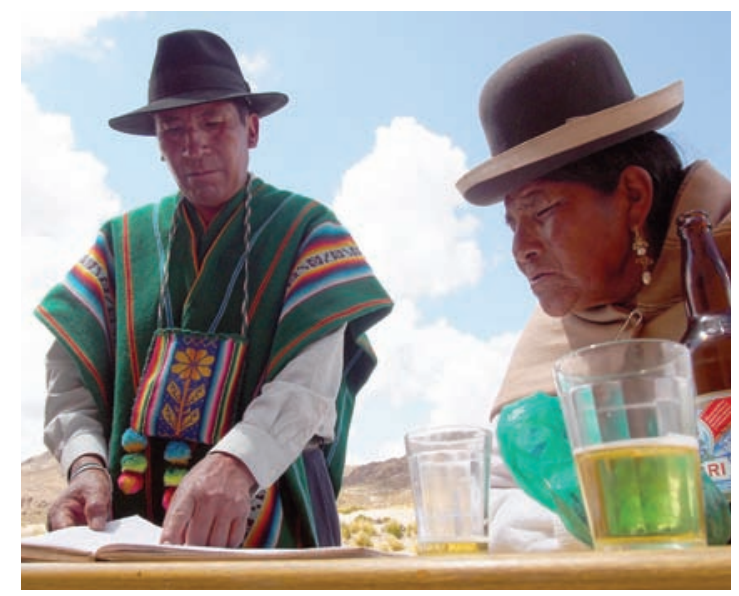

Figura 13. Los pagos se registran y se consultan (fotografía de Gerardo Mora). Figure 13. Payments are recorded and consulted (photo by Gerardo Mora).

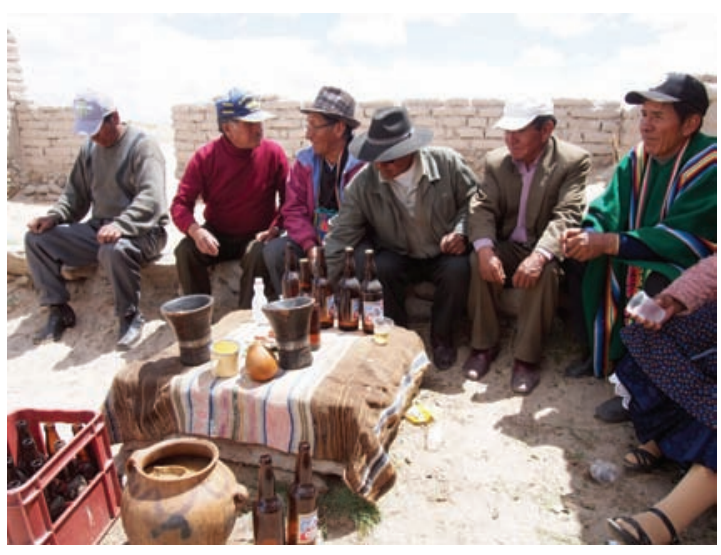

Figura 14. La mesa del cabildo (fotografía de Gerardo Mora). Figure 14. The table of the "cabildo" (photo by Gerardo Mora).

do. Luego a la casa del pasante, donde estaba la mesa dispuesta con los dos pares de choclos, los dos pares de papas y la jarra con chicha, pero ya sin el par de kerus.

Nos hemos acotado, por los límites propios de este tipo de publicaciones, a la participación de los kerus en la fiesta dedicada a la mamita Virgen del Rosario. Queda fuera una descripción de otros artefactos y organismos presentes en la fiesta, así como sus acciones en otras instancias comunitarias. No obstante, consideramos que ya hemos presentado antecedentes suficientes para realizar una reflexión final que nos permita complejizar nuestra comprensión de los kerus en tanto soportes en los sistemas de registro y comunicación andinos. 


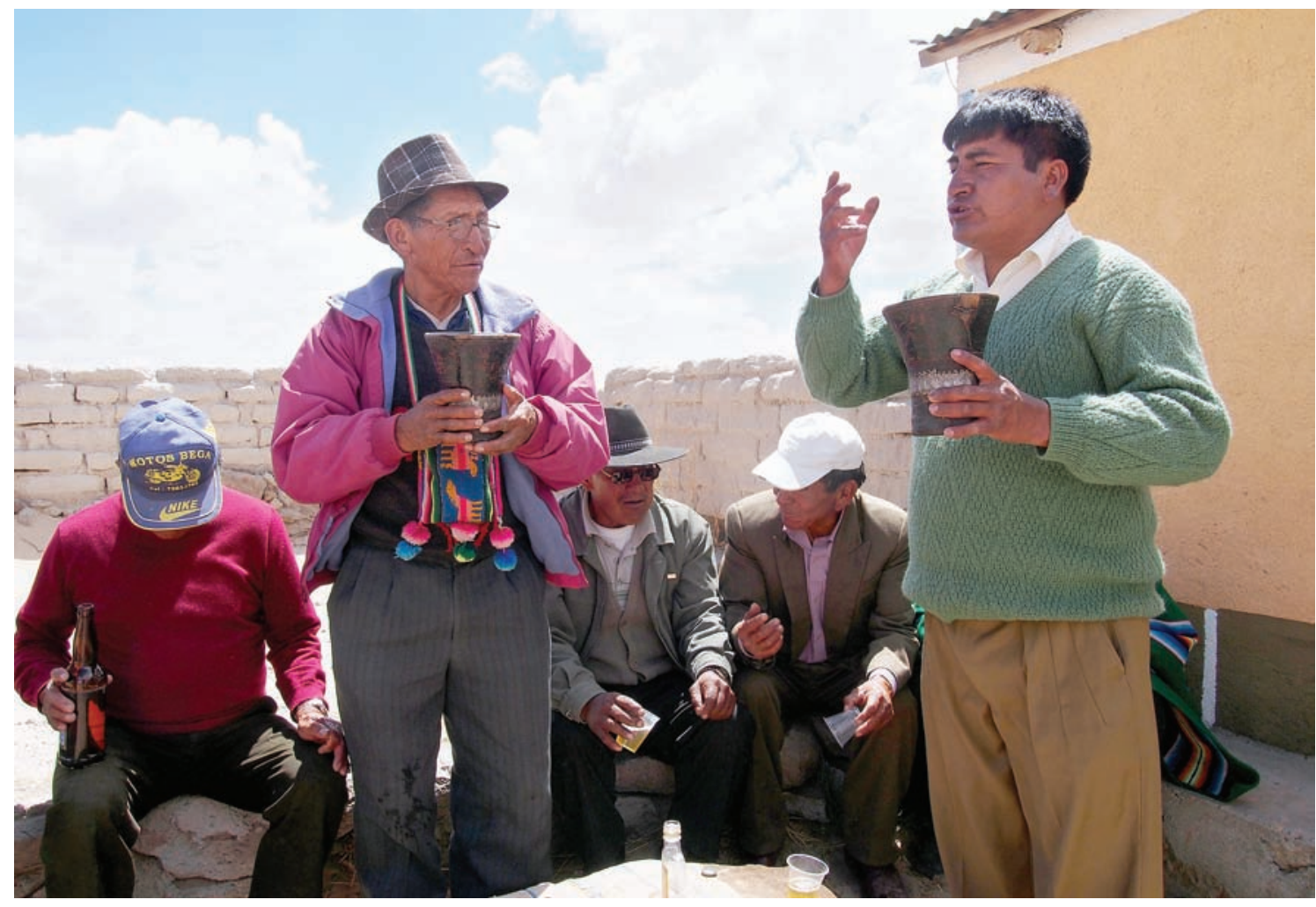

Figura 15. El profesor (fotografía de Gerardo Mora). Figure 15. The teacher (photo by Gerardo Mora).

\section{CACHARPAYA}

Dentro de los estudios andinos los kerus son, comúnmente, tratados y pensados como objetos terminados. Sin embargo, la evidencia en Soraga nos señala lo contrario. Los cuerpos de los kerus son reparados, modificados e intervenidos. Se les implantan prótesis de metal y resina, suturadas con alambres. Se trata de operaciones quirúrgicas que nos ayudan a comprender a los kerus como procesos activos, involucrados en la vida. Es decir, cuando observamos uno de estos artefactos no estamos ante un proyecto cerrado, un producto final o un objetivo logrado. Se trata de un artefacto que ha superado cierto "rito de pasaje" que lo ha llevado de un estado de preparación a otro de empleo (Hallam \& Ingold 2014: 2), sin que sus posibilidades de mutación se hayan disipado. Y los kerus, tal como sucede con otros artefactos, se comportan como organismos, por ejemplo, se pudren, como señalamos al principio.

A los kerus les acontecen situaciones similares a las vividas por los seres humanos. Sufren fracturas

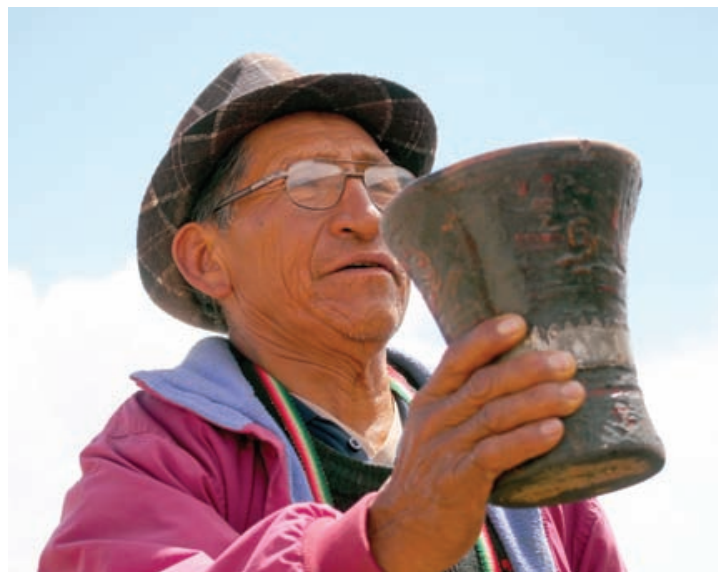

Figura 16. El juez (fotografía de Gerardo Mora). Figure 16. The judge (photo by Gerardo Mora).

que deben ser atendidas y sus cuerpos se degradan lentamente. Eso permite hablar de "participación" en vez de "uso". Por ello, nuestra pregunta no es cómo se usan los kerus en la fiesta, sino cómo participan los kerus en la fiesta. 
Los kerus son procesos, son artefactos que están viviendo (como si fueran organismos), en el entendido de que vivir implica constante cambio (putrefacción, fractura, prótesis, sutura, etc.). Podría argumentarse que son organismos cuyos cambios no son autogestionados, pues alguien vierte chicha en ellos y eso los pudre, a alguien se le caen y por eso se quiebran, alguien los interviene para repararlos, etc. Pero esto supondría que artefactos y organismos conforman un agregado de seres independientes, claramente delimitados y autónomos que pueden interactuar entre sí. En cambio, en este artículo proponemos que artefactos y organismos son procesos activos en constante movimiento, encuentro y mixtura.

Al comprender a los kerus como procesos socialmente involucrados, entonces podemos estudiar cómo ellos crean y hacen espacio-tiempo. Pues, tal como sus pieles llevan escenas de ñawpa pacha o de kay pacha, su presencia física también configura un determinado espacio-tiempo. En el caso de Soraga, se trata de un espacio y un tiempo donde la Iglesia católica, con sus hacedores y criaturas, está ausente, esto es, ñawpa pacha, un espacio-tiempo copresente con kay pacha, durante la fiesta del Rosario.

Por supuesto que no basta con la mera presencia de los kerus. Es la relación de copresencialidad entre los kerus y otros procesos (artefactos y organismos), como la mesa (con sus propios procesos organizados), como el pasante y las autoridades del ayllu (que no son solo personas, sino personas con ciertas investiduras, acciones, gestos, etc.), como el Niño Jesús (ataviado según corresponda), la llama en la fajcha, el estandarte del pasante, el calvario, su cerro y los cerros aledaños e, incluso, el sacerdote (que es también una persona con investiduras, acciones y gestos particulares) que acude a la localidad pero debe no vincularse con los kerus.

Tal como con otros organismos, no reciben solamente intervenciones directamente verificables. También recaen sobre ellos operaciones imperceptibles en sus cuerpos (por ejemplo: se dice que antes esas bandas eran de oro, pero que alguien las cambió por las actuales). De esta manera (so)portan una identidad, una memoria, que les es también constituyente. Cada keru no está hecho exclusivamente por lo que podríamos entender como su realidad material, cada keru está también hecho de las percepciones que se tienen de ese keru, en el sentido amplio del percibir y sus implicancias multisensiorales.

Esta relación entre semiosis andina y multisensorialidad se nos hace evidente. Primero, entendamos por semiosis un espacio-tiempo que contiene, al menos heurísticamente, prácticas de significación comprendidas por gentes diversas, sin que la distancia (topográfica o idiomática) incida en dicho movimiento de comprensión. Luego, para que tal movimiento comprensivo (llámese paso de un lenguaje a otro, de un contexto a otro, o bien lectoescritura, interpretación, representación, traslado, transcripción, transmutación, transliteración, etc.) sea posible, tales prácticas suceden multisensorialmente. Es decir, bajo el modelo hegemónico de los cinco sentidos, participan en ellas gusto (el sabor de la chicha, la carne del llamo, la hoja de coca), tacto (texturas de maderas, metales y resinas), oído (música de bronces, voces que conversan y challan, los sonidos propios de Soraga), vista (los seres en las pieles de los kerus, los propios kerus en la mesa, etc.) y olfato (humos, incienso y copal en contraste con el aroma de la madera remojada en chicha). Pero, además, es posible aunar tales sentidos en uno solo: el sentido del movimiento (tomar cada keru con las dos manos, inclinarlo para challar, alzarlo para brindar, hundir el rostro en la boca del keru para beber, pasarlo a otras personas, recibirlo, etc.), donde nociones kinésico-hápticas permiten dar cuenta de la complejidad en juego. Y donde también es posible incorporar imaginación, memoria e identidad como parte de ese sentido del movimiento.

Al crear espacio-tiempo los kerus hacen memoria/identidad local. Consideramos la memoria como inescindible de la identidad, en un continuo proceso de mutua creación, del cual ambos son resultados e insumos y donde el mnemotropismo es fundamental (ver Candau 1998; Morris-Suzuki 2005). Tal atracción por la memoria tiene también implicancias sensoriales. En relación con los kerus podríamos hablar de una memoria háptica (ver Gadelha et al. 2013), la que permite una aprehensión e identificación sensorial a través de su peso, textura, forma, volumen, etc., con independencia fisiológica de la visualidad, en la que solemos poner énfasis al estudiarlos.

En síntesis, en los kerus encontramos complejas relaciones sensoriales de memoria, identidad e imaginación, en las cuales se entretejen vínculos con el Inka, que podríamos considerar afectivos y emocionales. Recordemos, a modo de ejemplo, que los inkitas tenían los kerus en el socavón de la mamita. Tal vinculación es de carácter espacio-temporal, geopolítico e, incluso, reivindicatorio. 
De allí que la sola presencia de los kerus en Capital Ayllu Soraga remita, refiera y evidencie una importante filiación entre el ayllu Soraga y el Inka. Pero es también necesaria su participación (movimientos, presencias y contactos) en la fiesta de la mamita Rosario para resituar al ayllu geopolíticamente o, si prefiere, para crear ñawpa pacha, el espacio-tiempo donde-cuando Soraga era un ayllu importante, como cuentan los antiguos.

Actualmente, Capital Ayllu Soraga casi no aparece en las cartografías locales. Recién el año 2014 consiguieron aparecer en los mapas oficiales elaborados en el departamento de Oruro, gracias a las insistentes gestiones de algunos comuneros con buenos contactos en el municipio. Desde su perspectiva, la localidad se ha visto opacada por Sevaruyo, poblado cercano, estación ferroviaria, polo agrícola, con instalaciones de salud pública y educación formal más grandes, con mayor acceso a telecomunicaciones y otras aptitudes modernas que nublan la relevancia imperial que tuviera Soraga. ${ }^{19}$

En kay pacha, espacio-tiempo del colonialismo extirpador, el ayllu Soraga no es relevante. Pero como los kerus están hechos de relaciones con el Inka, fueron creados a propósito de esos vínculos, fueron creados para mantenerlos, mostrarlos y honrarlos, entonces los kerus pueden (re)crear el espacio-tiempo dondecuando esas relaciones eran procesos vigentes, incluso (re)activándolos como tales. Debido a que están hechos de relaciones con el Inka, en términos sensibles de vista, oído, tacto, olfato, gusto, imaginación, identidad y memoria, entonces pueden crear ñawpa pacha.

RECONOCIMIENTOS La presente publicación se realiza en el marco de una investigación todavía en curso, que es posible gracias a un acuerdo entre las autoridades del ayllu Soraga, Teófilo Paca, autoridad originaria, Martín Choque, corregidor, Silvestre Choque, promotor de las culturas; la autoridad del Municipio del Santuario de Quillacas, René Paca, alcalde; y, los autores, Andrea Goytia y Gerardo Mora, del proyecto FONDECYT 1130431. Durante nuestro trabajo de campo contamos con la colaboración de muchas personas en Capital Ayllu Soraga y con todas las facilidades para estudiar y acompañar a los kerus. Posteriormente, en Santiago de Chile, el material de terreno fue discutido con los integrantes del proyecto FONDECYT 1130431 y en una reunión de colaboración internacional de dicho equipo junto a los investigadores Verónica Cereceda y Frank Salomon, en enero de 2015. Además, este proceso escritural contó con la colaboración de las investigadoras Ximena Mazzei, Sandra Coppia y Soledad Martínez; y con los valiosos aportes de tres evaluadores externos. Agradecemos a todos ellos su generosa y gentil colaboración. Y asumimos la exclusiva responsabilidad de las falencias y carencias de este documento.

\section{NOTAS}

${ }^{1}$ Este trabajo es resultado del proyecto FONDECYT 1130431.

${ }^{2}$ En Ayllu Soraga se señala que la escritura de la palabra es /keru/, diferenciándose así de una tradición lingüística que ha privilegiado la forma /qeru/. Documentos de distinta data, incluso desde el siglo XIX, confirman esta forma escrituraria en la región.

${ }^{3}$ Un informe realizado por el licenciado Ludwing Cayo, arqueólogo, señala que "la primera apertura de la estructura se dio a fines del siglo XIX" (2010: 2). En este artículo exponemos los antecedentes que reunimos en nuestras estadías en Soraga. Contrastarlos con el citado documento puede levantar valiosas inquietudes.

${ }^{4}$ ¿Por qué asociarla con un socavón?, ¿se tratará de una virgen ctónica? Al respecto, la investigadora Verónica Cereceda (comunicación personal), sugiere explorar la posibilidad de que corresponda a una virgen saqra, y no gloria, como podría suponerse.

5 "Inkitas", diminutivo de "Inkas". Otro nombre para mallkinaka, cuerpos humanos momificados envueltos en un ajuar fúnebre, que se consideran vinculados genealógicamente al Inka.

${ }^{6}$ El pasante corresponde a un cargo de rotación anual, también llamado "alférez". Es quien se ha comprometido a procurar (financiera y logísticamente) la adecuada realización de la fiesta. Cuentan que antes, en Capital Ayllu Soraga, eran cuatro pasantes: dos mayordomos y dos alféreces.

${ }^{7}$ Así, la palabra keru, en este artículo, puede indicar uno o dos vasos ceremoniales.

8 "Chachir Kuma", según Cayo (2010: 5).

${ }^{9}$ Los tocapus son cuadrángulos rellenos con formas geométricas y colores, presentes en textiles y qerus.

10 “Kalis", según Cayo (2010: 5).

${ }^{11}$ Corresponde recordar en este punto las aquillas, vasos elaborados, principalmente durante la Colonia, en oro y plata.

${ }^{12}$ Agradecemos a las investigadoras Carla Díaz y Gabriela Acuña sus análisis, indicaciones y recomendaciones sobre esta cronología.

${ }^{13}$ Sobre la mesa, ver Martínez Soto-Aguilar (1987) y Fernández (1995).

${ }^{14}$ Pensamos la expresión challar como "arrojar, en cantidades equivalentes a un sorbo, un puñado o una pizca, alguna cosa que pueda fluir (polvos, hojas, líquidos, etc.) sobre algo o alguien a modo de interacción para ser/hacer" (Mora 2015: 225).

${ }^{15} \mathrm{La}$ expresión apxata nos fue explicada como "el compromiso que hicieron para compartir", el cual es registrado por escrito, cuidadosamente, en un cuaderno. Por su parte, el lingüista Teófilo Laime, de la comunidad Sullqa Titi, propone que apxata viene de "ap-xata", esto es, el verbo "apaña" (llevar algo en las manos) con el sufijo -xata (colocar encima). Se trata de una actividad donde los acompañantes acuden con algo (merienda, regalo u otro) para generar el ayni, todo familiar e invitado va con apxata, esto ocurre en varias fiestas rituales (Teófilo Laime, comunicación personal).

${ }^{16}$ Sobre la relación entre humor y sacralidad, ver Martínez SotoAguilar (1974).

${ }^{17}$ Cabe apuntar que en algunos kerus hay escenas de libación con éstos en compañía de hombres que tocan instrumentos autóctonos, en una especie de ceremonia similar a la aquí reseñada.

${ }^{18}$ Gerardo Mora, coautor de este artículo, ofició de secretario cobrador. Al parecer, un cargo improvisado pero propicio, donde su condición de licenciado -a ese momento- daba mayor solemnidad y diversión al acto. Emitió recibos y dejó constancias en el libro. Tam- 
bién debió defender el alza de la contribución, evadir el contacto directo con el dinero, beber en cada pago y sortear las bromas.

${ }^{19}$ Es necesario señalar que esta comprensión de Sevaruyo se hace desde Soraga. En Sevaruyo se están viviendo cambios acelerados y peligrosos. Las familias de Sevaruyo pasaron, en menos de diez años, de una economía de subsistencia a una mercantil, gracias a la producción extensiva de quinua, la cual ha favorecido la inversión en maquinaria, la llegada de mano de obra y la explotación intensiva de grandes superficies de tierra, pues dicho grano ha sextuplicado su valor comercial, reduciendo así el interés en criar ganado; por ello, aunque reconocen cierto auge económico, lamentan el daño ecológico, pues para tener un desarrollo agropecuario sostenible, agricultura y ganadería deben ir como chacha-warmi, es decir, en (un ideal de) complementariedad armónica, donde la cantidad de abono que pueden proveer los animales incide en la distribución y cobertura de los cultivos (PNUD-Bolivia 2010: 154155). Situación similar, pero mucho menos intensa a la que se vive en Soraga, donde no ha llegado mano de obra ajena al ayllu, la tecnificación de los procesos apenas cumple con las exigencias de los mercados internacionales y la ganadería mantiene vigencia. Sin embargo, ya hay conflictos por derechos de tierra, probablemente ante la necesidad, impuesta por la mercantilización de la quinua, de expandir los cultivos.

\section{REFERENCIAS}

Bertonio, L., 1984 [1612]. Vocabulario de la lengua aymara. Cochabamba: Centro de Estudios de la Realidad Económica y Social.

Candau, J., 2005. Anthropologie de la mémoire. Paris: Armand Colin, Collection Cursus Sociologie.

CAYo, L., 2010 Ms. Informe Técnico de Descargo UNAR PI. 250/10. Estado Plurinacional de Bolivia. Ministerio de las Culturas. 12 de agosto de 2010. La Paz.

Cereceda, V., 2010. Semiología de los textiles andinos: Las talegas de Isluga. Chungará 42 (1): 191-198.

Chaiña Flores, E., 2015. Del kero colonial al kero republicano. La vida \& la historia 4: 7-18.

DíAz, A., 2009. Los Andes de bronce: Conscripción militar de comuneros andinos y el surgimiento de las bandas de bronce en el Norte de Chile. Historia 42 (2): 371-399.

$<$ http://www.scielo.cl/scielo.php?script=sci_arttext\&pid=S0717$71942009000200002 \& \operatorname{lng}=$ es\&tlng=es. $10.4067 /$ S07 17 71942009000200002> [consultado 12-05-15]

Fernández, G., 1995. El Banquete Aymara: Mesas y yatiris. La Paz: Hisbol.
Flores Ochoa, J.; E. Kuon \& R. Samanez, 1998. Arte Inka en vasos ceremoniales. Colección Arte y Tesoros del Perú. Lima: Banco de Crédito del Perú.

Gadelha, M.; J. Silva, M. Andrade, D. Viana, B. Calvo \& N. SanTOS, 2013. Haptic memory and forgetting: A systematic review. Estudos de Psicologia (Natal) 18 (1): 131-136.

Gisbert, T.; S. Arze \& M. Cajías, 2010. Arte textil y mundo andino. La Paz: Plural editores.

Hallam, E. \& T. Ingold, 2014. Making and growing: An introduction. En Making and growing. Anthropological studies of organisms and artefacts, E. Hallam \& T. Ingold, Eds., pp. 1-24. London: Ashgate.

InGOLD, T., 2015. The life of lines. London: Routledge.

Instituto Nacional de Estadísticas-Programa de las NaCiones Unidas para el Desarrollo, 2005. Bolivia: Atlas estadístico de municipios. La Paz: INE-PNUD.

MARTÍNEZ, G., 1974. Humor y sacralidad en el mundo autóctono andino. Iquique: Universidad de Chile.

Martínez, G., 1987. Una mesa ritual en Sucre: Aproximaciones semióticas al ritual andino. La Paz: Hisbol-Asur.

MartíneZ, J. L., 2012. El virrey Toledo y el control de las voces andinas coloniales. Colonial Latin American Review 21: 175-208.

Martínez, J. L.; C. Díaz, C. Tocornal \& V. Arévalo, 2014. Comparando las crónicas y los textos visuales andinos: Elementos para un análisis. Chungara 46 (1): 91-114.

Martínez, J. L., C. Díaz \& C. Tocornal, 2016. Inkas y antis: Variaciones coloniales de un relato andino visual. Boletín del Museo Chileno de Arte Precolombino 21 (1), en prensa.

Martínez, R., 2001. Autour du geste musical andin. Cahiers dethnomusicologie 14: 167-180.

Mora, G., 2015. Hacer familia con la cuenca de San Pedro-Inacalari. Tesis para optar al grado de Magíster en Asentamientos Humanos y Medio Ambiente, Pontificia Universidad Católica de Chile.

Mora, G. \& C. Odone, 2011. Niño Jesús en Cuzco colonial y Azapa contemporáneo: Un ejercicio de análisis de bultos como soportes. Boletín del Museo Chileno de Arte Precolombino 16 (2): 61-74.

Morris-Suzuki, T., 2005. The past within us. Londres-Nueva York: Verso.

PLATT, T., 1986. Mirrors and maize: The concept of yanantin among the Macha of Bolivia. En Anthropological History of Andean polities, J. Murra, N. Wachtel \& J. Revel, Eds., pp. 228-259. Cambridge: Cambridge University Press.

Pnud-Bolivia, 2010. Territorio, desigualdades y estrategias de movilidad social en los pueblos indígenas: Cinco estudios de caso. La Paz: Programa de las Naciones Unidas para el Desarrollo.

RAmos, L., 2006. Las vasijas de madera ornamentadas con laca utilizadas por los dirigentes andinos de la época colonial: Función y tipología de sus formas. Revistas de Antropología Americana 36: 83-117. 